\title{
DE LA MOVILIZACIÓN TRADICIONAL A LAS REDES DE PRESIÓN TRANSNACIONAL: VIOLENCIA ANTISINDICAL Y DERECHOS HUMANOS EN COLOMBIA
}

\author{
Jairo Antonio López Pacheco \\ SANDRa Hincapié JimÉnez
}

\section{INTRODUCGIÓN}

DESDE LOS PRIMEROS INTENTOS de organización del movimiento obrero en Colombia en la década de 1920 hasta nuestros días, la persecución y violencia contra el sindicalismo ha sido una constante. ${ }^{1}$ Dicha realidad se volvió más crítica tras la expansión de la guerra y el conflicto armado en las tres últimas décadas, ya que los trabajadores sindicalizados sufrieron un agudo proceso de victimización que dejó entre 1979 y 201011565 casos de violaciones de sus derechos a la vida, la libertad y la integridad personal, directamente relacionados con el derecho de libertad de asociación y

${ }^{1}$ Dentro de los diversos estudios históricos, véase Charles Bergquist, Los trabajadores en la historia latinoamericana. Estudios comparativos de Chile, Argentina, Venezuela y Colombia, Bogotá, Siglo XXI, 1988; Charles Bergquist, "Los trabajadores del sector cafetero y la suerte del movimiento obrero en Colombia 1920-1940", en Gonzalo Sánchez y Ricardo Peñaranda (coords.), Pasado y presente de la violencia en Colombia, Medellín, La Carreta, 2007; Mauricio Archila, Cultura e identidad obrera: Colombia 1910-1945, Bogotá, Cinep, 1991; Álvaro Delgado, "El conflicto huelguístico colombiano, 1961-1990”, en ¿Dónde está la clase obrera? Huelgas en Colombia 1946-1990, Bogotá, Cinep, 1995; Daniel Pecaut, Política y sindicalismo en Colombia, Bogotá, La Carreta, 1973. 
participación política. ${ }^{2}$ A pesar de lo dramático y visible de dicha situación, el Estado colombiano nunca reconoció el problema de la violencia contra los sindicalistas como una situación sistemática y alarmante en materia de derechos humanos; por el contrario, las actitudes de señalamiento, estigmatización y desconocimiento del sindicalismo y su rol político han caracterizado el comportamiento de los diferentes gobiernos y autoridades. ${ }^{3}$

En el presente artículo analizamos cómo la convergencia de actores nacionales e internacionales en medio de la firma y ratificación del Tratado de Libre Comercio entre Colombia y Estados Unidos (2004-2011) configuró una red transnacional de presión que en poco tiempo logró efectos materiales y simbólicos no conseguidos hasta el momento a pesar de la continuidad histórica de la violencia antisindical en Colombia. Nuestra tesis principal plantea que las redes de presión transnacional lograron erigirse como dispositivo efectivo de denuncia y reivindicación de derechos humanos reemplazando las antiguas formas de movilización tradicional de los sindicatos que no habían logrado generar sanciones ni reconocimiento gubernamental frente a la violencia de la que eran víctimas. Primero, presentamos la discusión teórico-metodológica sobre la movilización transnacional en defensa de los derechos humanos. Segundo, describimos la violencia contra los sindicalistas en Colombia como una constante histórica. Tercero, descomponemos la red transnacional de defensa de acuerdo a los actores involucrados y los mecanismos de interacción que permitieron la intermediación y la difusión de las demandas contra la violencia antisindical. Finalmente, subrayamos los resultados de la presión transnacional en sus dimensiones material y simbólica.

${ }^{2}$ Comisión Colombiana de Juristas y Escuela Nacional Sindical, Imperceptiblemente nos encerraron. Exclusión del sindicalismo y lógicas de la violencia antisindical en Colombia 1979-2010, Bogotá, ENS-CCJ, 2012, p. 35.

${ }^{3}$ Alexander Pereira, "Violencia en el mundo sindical. Un análisis cualitativo sobre una práctica persistente en Colombia, 1986-2011”, Revista Controversia, núm. 198, 2012; Mauricio Archila, "Luchas laborales y violencia contra el sindicalismo en Colombia 2002-2010. ¿Otro daño colateral de la seguridad democrática?”, Revista Controversia, núm. 198, 2012. 


\section{LOS DERECHOS HUMANOS Y LA MOVILIZACIÓN TRANSNACIONAL}

En las últimas décadas los derechos humanos han representado un medio de articulación colectiva que presenta escenarios de movilización y protesta frente a los gobiernos, constituyéndose en motor de conflictos políticos. ${ }^{4}$ Según Stammers, la doble relación como marco normativo internacional institucionalizado (top-down power) y como mecanismo de defensa individual y colectivo (down-up power) inscribe a los derechos humanos en complejas y ambiguas relaciones de poder. Los movimientos sociales que históricamente han reclamado el reconocimiento y respeto de los derechos se han visto inscritos en una tendencia de formalización del activismo de su defensa que puede llevar a perder el carácter contencioso de las demandas al ser parte de las propias lógicas institucionales. ${ }^{5}$

La corriente de las relaciones internacionales ha elaborado los principales marcos analíticos para el estudio de la movilización en defensa de los derechos humanos, en tanto el derecho internacional de los derechos humanos y el cuerpo normativo y valorativo de los mismos se han institucionalizado a partir de un proceso de transnacionalización del derecho y la política, ${ }^{6}$ cuyos énfasis han estado en los procesos de "cambio del comportamiento estatal". ${ }^{7}$ Dentro de estas discusiones, los marcos teóricos más influyentes han sido los modelos del Boomerangy la Espiral, los cuales tratan de demostrar cómo dentro de los Estados se socializan y consolidan

${ }^{4}$ Jairo López, "Los derechos humanos en movimiento. Una revisión teórica contemporánea”, Revista Espiral. Estudios de Estado y Sociedad, núm. 56, 2013.

${ }^{5}$ Neil Stammers, Human Rights and Social Movements, Londres, Pluto Press, 2008.

${ }^{6}$ Bryant Garth, "The Globalization of the Law", en The Oxford Handbook of Law and Politics, Oxford, Oxford University Press, 2008; Yves Dezalay y Bryant Garth, "From the cold war to Kosovo: the rise and renewal of the Field of International Human Rights", Annual Review of Law and Social Science, núm. 2, 2006.

${ }^{7}$ Alejandro Anaya, "Los derechos humanos desde las relaciones internacionales: normas, regímenes, emprendedores y comportamiento estatal”, en Ariadna Estévez y Daniel Vázquez (coord.), Los derechos humanos en las ciencias sociales. Una perspectiva multidisciplinaria, México, Flacso-Cisan-unam, 2010; Sonia Cárdenas, Conflict and Compliance: State Responses to International Human Rights Pressures, Philadelphia, University of Pennsylvania Press, 2007. 
patrones de respeto a los derechos humanos por medio de ciclos de presión materializados, entre otras, en las ratificaciones de tratados que obligan a la modificación de viejas prácticas. ${ }^{8}$

El modelo del Boomerang y de la Espiral fue utilizado para analizar los cambios generados por la presión transnacional sobre regímenes autoritarios en los cuales los actores colectivos nacionales no podían incidir, lo cual obligó a los actores colectivos nacionales a buscar conexiones "hacia afuera" con otros gobiernos que se identificasen con la defensa de los derechos humanos, presión que regresaba con un efecto fortalecido "de afuera hacia adentro". Las etapas que caracterizan el modelo son: primero, la "negación" por parte de los Estados frente a los reclamos colectivos y las propias normas de los derechos humanos; segundo, "concesiones tácticas" que llevan a modificaciones discursivas o de prácticas institucionales menores por parte de los Estados que, al mismo tiempo, empiezan a reconocer la validez de los derechos humanos; tercero, el "estatus prescriptivo", el cual hace referencia a una instancia avanzada de la presión transnacional en la que los Estados adoptan el lenguaje de los derechos humanos bajo una "lógica argumentativa", y por medio de reformas legales buscan incorporar los derechos al entramado institucional; finalmente, un "cambio de prácticas estatales" relacionadas con el respeto efectivo de los derechos humanos como respuesta a la presión transnacional. ${ }^{9}$

Aunque las etapas del modelo Boomerang y Espiral no son lineales (puede existir avance y retroceso), lo cierto es que este enfoque busca identificar en qué momento se encuentra la presión

${ }^{8}$ Susan Burgerman, Moral Victories: How Activists Provoke Multilateral Action, Ithaca, Cornell University Press, 2001; Sanjeev Khagram, James Riker y Kathryn Sikkink, Restructuring World Politics: Transnational Social Movements, Networks, and Norms, Minneapolis, University of Minnesota Press, 2002; Beth Simmons, Mobilizing for Human Rights: International Law in Domestic Politics, Cambridge, Cambridge University Press, 2009.

${ }^{9}$ Margaret Keck y Kathryn Sikkink, Activistas sin fronteras. Redes de defensa en política internacional, México, Siglo XXI, 2000; Thomas Risse, Stephen Ropp y Kathryn Sikkink, The Power of Human Rights: International Norms and Domestic Change, Cambridge, Cambridge University Press, 1999. 
sobre los Estados, y tiene como premisa la idea según la cual a mayor densidad y continuidad de la presión transnacional, mayor capacidad de transitar de una a otra etapa del comportamiento estatal. $^{10}$

Lo específico del estudio de las etapas de la presión en los modelos Boomerang y Espiral es que se fundamentan en el trabajo de "redes transnacionales" donde participan diferentes actores tanto estatales como no estatales, los cuales "comparten creencias, valores y normas [...] significados sociales, políticos y culturales". ${ }^{11}$ Dichas redes trasnacionales actúan por medio de campañas, condenas morales, políticas de avergonzamiento, entre otras, que se elaboran en principio como parte del intercambio de información y servicios de manera "transparente y horizontal". ${ }^{12}$ Las redes de presión se forman principalmente por organizaciones no gubernamentales nacionales e internacionales, órganos especializados de derechos humanos, agencias o funcionarios de gobiernos que defienden los principios democráticos y el régimen internacional de derechos humanos.

La evaluación de los efectos de la defensa de los derechos humanos por medio de redes transnacionales se ha definido en un doble ámbito. Por un lado están los efectos materiales, que se presentan cuando se involucran a otros gobiernos poderosos que condicionan programas de ayuda o cooperación a cambio de ciertas prácticas, siendo específicamente los gobiernos u organismos multilaterales como el Banco Mundial o la onu los que pueden ejercer sanciones materiales. Por otro lado, están los efectos simbólicos relacionados con la producción de información y visibilización de los problemas de violación de derechos humanos, los cuales son impulsados principalmente por las organizaciones no gubernamentales u otro tipo de actores de las redes que no tengan capacidades

${ }^{10}$ Emma Maza, Derechos humanos. México: retórica sin compromiso, México, Flacso, 2009; Anaya, Alejandro, El país bajo presión. Debatiendo el papel del escrutinio internacional de derechos humanos sobre México, México, cide, 2012.

${ }^{11}$ Keck y Sikkink, op. cit., 2000, p. 20.

12 Risse, Ropp y Sikkink, op. cit., 1999; Keck y Sikkink, op. cit., 2000; Burgerman, op. cit., 2001. 
de ejercer sanciones vinculantes o de obligatoriedad, pero que ejercen presión sobre los gobiernos. ${ }^{13}$

Ahora bien, a pesar de la institucionalización de la democracia procedimental y un reconocimiento de los gobiernos de la importancia del respeto de los derechos humanos como horizontes morales de expectativa en toda América Latina (que se ve reflejado en la firma y ratificación de tratados de derechos humanos así como en la creación de órganos estatales especializados), las violaciones a los derechos humanos son una constante generalizada en el continente, razón por la cual las redes de presión transnacional han formalizado e institucionalizado cada vez más su acción (siendo fundamentales en diversas áreas como la defensa del medio ambiente, de los migrantes, del comercio justo, entre otras). La tendencia creciente a la "expulsión" de las demandas al nivel de las redes transnacionales se explica porque los recursos con los que cuentan los actores colectivos nacionales se potencian en el nivel transnacional al ensanchar la capacidad de influencia y, con ello, logran mayor poder de persuasión que las formas tradicionales de movilización. Las demandas de la movilización transnacional pueden variar en tipos y temas, pero en dicha "expulsión" configuran ya redes, coaliciones o movimientos transnacionales, los cuales se distinguen por el tipo de conexiones que elaboran, siendo el intercambio de información, las tácticas coordinadas y la movilización conjunta sus principales medios respectivamente. ${ }^{14}$

Los derechos humanos, como un repertorio de contienda aprendido y delimitado por el proceso de "transnacionalización de la política y descentralización de los recursos estatales", ${ }^{15}$ han presentado adaptaciones diferenciadas de antiguas formas de

${ }^{13}$ Olga Aikin y Alejandro Anaya, "Crisis de derechos humanos de las personas migrantes en tránsito por México: redes y presión transnacional”, Foro Internacional, vol. 53, núm. 1, 2013; Alejandro Anaya, El país bajo presión, México, cide, 2012.

14 Kathryn Sikkink, "La dimensión transnacional de los movimientos sociales”, en Elizabeth Jelin, Más allá de la nación: las escalas múltiples de los movimientos sociales, Buenos Aires, Libros del Zorzal, 2003.

${ }^{15}$ Sidney Tarrow, The New Transnational Activism, Cambridge, Cambridge University Press, 2005, p. 99. 
movilización a nuevas intermediaciones internacionales. ${ }^{16}$ En todos los casos de acción colectiva transnacional las conexiones se fomentan al momento en que se comparten marcos de demanda. Un marco es el conjunto de creencias y significados que simplifica y condensa la realidad a través de la selección, codificación y señalamiento de situaciones, orientados hacia la acción, que legitiman las actividades de una movilización. ${ }^{17}$ Nuestro caso de estudio permite analizar cómo bajo el marco de demanda de los derechos humanos, las denuncias de la violencia antisindical que hasta el momento se habían desarrollado en el nivel doméstico lograron generar conexiones y articular una red de presión más allá de las fronteras; a pesar de que la violencia contra los sindicalistas había sido una constante histórica en Colombia, la demanda colectiva transnacional encontró en la firma del TLC una ventana de oportunidad y logró tener efectos no alcanzados hasta el momento.

Para llegar a dicha explicación, nos preguntamos: ¿cuál es la característica de dicha violencia antisindical?, ¿cuáles son los actores que se integraron a la red de presión transnacional?, ¿cuáles fueron los mecanismos de intermediación y difusión de la red transnacional?, ¿qué tipo de efectos sobrevino tras la contienda impulsada por la red de presión?

\section{La violencia contra los Sindicalistas en Colombia}

La violencia sufrida por los sindicalistas tiene una constante histórica, relacionada directamente con el proceso político colombiano

16 "Los actores políticos utilizan las reclamaciones de violaciones de derechos humanos para avanzar en su posición de negociación y debilitar a sus opositores. Entran en las competiciones que demanda el escenario internacional, con el fin de conseguir apoyo extranjero para su agenda [económica y política]". Margaret Hagan, "The Human Rights Repertorie: Its Strategic Logic, Expectations and Tactics”, International Journal of Human Rights, vol. 14, núm. 4, 2011, p. 559.

${ }^{17}$ David Snow y Robert Benford, "Alternative Types of Cross-national Diffusion in the Social Movement Arena”, en Social Movements in a Globalizing World, Basingstoke, Macmillan, 2009; Robert Benford y David Snow, "Framing Processes and Social Movements: An Overview and Assessment", Annual Review of Sociology, vol. 26, 2000. 
y el conflicto político armado. En medio del escalonamiento del conflicto armado provocado por la expansión de los ejércitos paramilitares en los últimos treinta años, los trabajadores sindicalizados al igual que líderes sociales y comunitarios fueron perseguidos en procesos de estigmatización sociopolítica donde se relacionaba al sindicalismo y las reivindicaciones redistributivas con la actividad subversiva. ${ }^{18}$ Particularmente, los sindicalistas han sufrido una violencia sostenida que se manifiesta en una gran cantidad de violaciones a sus derechos a la vida y la libertad. Algunos autores han calificado dicha estrategia de violencia y persecución como la búsqueda del "exterminio sindical"; ${ }^{19}$ sólo los homicidios contra sindicalistas registraron desde 1986 hasta 2010 un total de 1858 muertes violentas, y tan sólo en el periodo 2000 y 2010 un total de 1057 según la Escuela Nacional Sindical y 975 según el Observatorio de Derechos Humanos de la Presidencia (véase la gráfica 1).

\section{GRÁFICA 1}

Homicidios de sindicalistas en Colombia 1986-2010

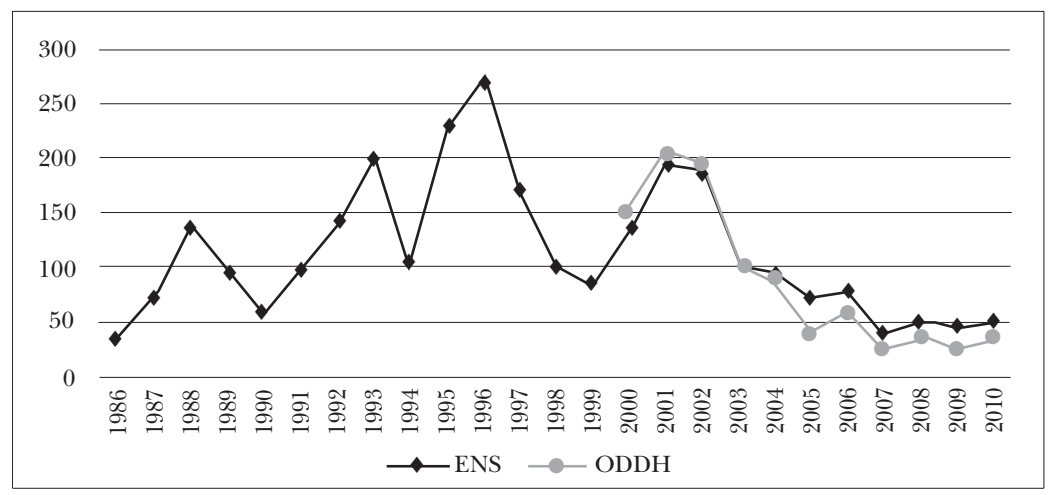

Fuente: Escuela Nacional Sindical y Observatorio de Derechos Humanos y Derecho Internacional Humanitario de la Presidencia de la República.

18 Sandra Hincapié, "Órdenes yuxtapuestos. Dinámicas contenciosas, reformas estatales y crimen organizado en México y Colombia”, tesis de doctorado, México, Flacso, 2013.

${ }^{19}$ Archila, op. cit., 2012. 
Los homicidios son la máxima expresión de la persecución y sistemática violación de derechos humanos experimentada por los sindicatos. ${ }^{20}$ Las agrupaciones de trabajadores más afectadas fueron la Federación Colombiana de Educadores con 954 casos $(32.7 \%)$, el Sindicato Nacional de Trabajadores de la Industria Agropecuaria con 792 casos $(27.1 \%$ ) y la Unión Sindical Obrera de la Industria del Petróleo con 116 casos (4\%). Los principales municipios afectados fueron Apartadó (263), Turbo (257), Medellín (172), Chigorodó (117), Carepa (114) y Barrancabermeja (127). La asociación entre sindicalismo e insurgencia sirvió como retórica justificadora en la persecución y exterminio de los sindicalistas por parte de los actores armados estatales y paramilitares. La sistemática estigmatización a la actividad sindical conllevó el detrimento de los intereses de los trabajadores y favoreció los intereses de los grandes capitales, de ahí que el patrón de violencia estuvo ligado a las regiones y zonas de interés económico estratégico como las empresas de enclave bananero y minero, entre otras. ${ }^{21}$

Como casos paradigmáticos de la violencia antisindical en Colombia y su relación directa con la expansión de la guerra y la consolidación del dominio paramilitar en zonas de interés económico estratégico, encontramos la violencia antisindical en la región de Urabá en un enclave bananero y en la región del Cesár en medio del proceso de extracción minera. Por una parte, en la región de Urabá los empresarios bananeros apoyaron abiertamente la formación de ejércitos paramilitares brindando financiamiento pero también siendo agentes activos dentro de la filas de los ejércitos paramilitares. ${ }^{22} \mathrm{Al}$ respecto Hébert Veloza García, alias H. H.,

20 CUT, CGT y CTC, Los derechos laborales y las libertades sindicales en Colombia, Bogotá, s. e., 2007.

${ }^{21}$ Sobre la escenificación de la guerra, véase Sandra Hincapié, La guerra en las ciudades, Medellín, IPC, 2005. En torno a la dinámica regional de la guerra, véase Sandra Hincapié, "Estado y región: Colombia y Perú en perspectiva comparada”, en ¿Prolongación sin solución? Perspectivas sobre la guerra y la paz en Colombia, Bogotá, Universidad Externado de Colombia, 2012.

${ }^{22}$ Como es el caso de Raúl Hasbún, hijo de uno de los primeros colonizadores y pioneros del empresariado bananero en la región, que llegó a ser miembro activo y jefe del bloque bananeros de las Auc. En una de las declaraciones de un 
jefe paramilitar, declaró ante un juez que "quienes más salieron favorecidos de esta guerra en Urabá fueron los empresarios". ${ }^{23} \mathrm{El}$ caso más relevante es la empresa Chiquita Brands International, que se declaró culpable el 17 de septiembre de 2007 por el delito de "involucrarse en transacciones con terroristas globales especialmente designados" ante el Juzgado del Distrito de Columbia (EE. UU.); fue condenada a pagar 25 millones de dólares (aunque su pago fue diferido en cómodas cuotas de 5 millones anuales, pena irrisoria considerando la capacidad económica de la empresa). ${ }^{24}$ Además del financiamiento que brindó Chiquita Brands a los grupos paramilitares en Colombia, las investigaciones realizadas para documentar el caso lograron establecer cómo a través de su filial, Bananos de Exportación S.A. Banadex, las instalaciones sirvieron en el tráfico y almacenamiento de armas para los grupos paramilitares, fusiles AK-47 y 2.5 millones de municiones. ${ }^{25}$

El segundo caso paradigmático es el de la empresa minera Drummond, la cual también ha debido enfrentar procesos en Estados Unidos acusada de financiar grupos paramilitares y promover el asesinato a manos del crimen organizado de los líderes sindicales Valmore Locarno y Víctor Hugo Orcasita. Los trabajadores se desempeñaban como presidente y vicepresidente del Sindicato Nacional de Trabajadores de Empresas Mineras y Energéticas (Sintramienergética). El 12 de agosto de 2001 fueron

jefe paramilitar ante los jueces de Justicia y Paz, relató: "a finales de 1997, el jefe paramilitar Raúl Hasbún, conocido con el alias de Pedro Bonito, llegó a un acuerdo con varias bananeras de la región de Urabá, entre las que se encuentran Chiquita Brands, Banacol, Delmonte, Dole, Proban y Uniban, que pagaban tres centavos de dólar por caja exportada a las autodefensas. Este pago se hacía a la Convivir Papagayo, y se destinaba una parte para Carlos Castaño, otra para obras sociales y una tercera parte para el pago de policías corruptos”, Verdad Abierta, 3 de febrero de 2009.

${ }^{23}$ El Colombiano, "La verdad no se cuenta en un día", 13 de julio 2008.

${ }^{24}$ EEUU contra Chiquita Brands International: Memorando de Condena del Gobierno. Juzgado del Distrito de Columbia, EE.UU., No. Criminal 07-055 (RCL), Septiembre 17 de 2007.

${ }^{25}$ Revista Semana, "Banana 'para-republic'”, 17 de marzo de 2007; oEA, "Informe de la Secretaría General sobre el desvío de armas nicaragüenses a las Autodefensas Unidas de Colombia”, 29 de enero de 2002. 
obligados por un grupo de paramilitares a bajar de un transporte público, cuando se dirigían hacia el municipio de El Paso, y posteriormente fueron asesinados. ${ }^{26}$ Es importante resaltar además que Gustavo Soler Mora, quien asumió la presidencia del sindicato, fue desaparecido el 5 de octubre de 2001; su cuerpo sin vida fue hallado con signos de tortura dos días después en una carretera de la Jagua de Ibirico. ${ }^{27}$ En abril de 2012 el empresario Blanco Maya reconoció su participación como intermediario entre la empresa Drummond y las organizaciones paramilitares; según su testimonio, la empresa minera financió al Bloque Norte por medio de sobrecostos en el cobro de alimentación que recaudó su empresa Industrial de Servicios y Alimentos ISA; señaló además que la empresa financió de manera voluntaria a las organizaciones criminales desde mediados de la década de 1990 y que sindicó a varios de sus funcionarios, entre ellos al entonces jefe de seguridad James Atkins. ${ }^{28}$ La persecución a la asociación sindical por parte de la empresa minera, a través de las organizaciones criminales del paramilitarismo, ha llevado a un detrimento en las condiciones laborales de los trabajadores mineros, quienes ahora son en su mayoría subcontratados por medio de agencias donde el trabajador asume todos los riesgos de su actividad. ${ }^{29}$

En medio de dicho escenario adverso, la defensa de los derechos humanos se constituyó en el centro de las demandas y la movilización de denuncia por parte de las organizaciones sindicales. La defensa de la libertad de asociación y la vida fueron objetivo de acción no sólo de los sindicalistas, sino también de las organizaciones defensoras de derechos humanos; fortalecieron sus lazos interinstitucionales, promovieron el ejercicio de acciones coordinadas

${ }^{26}$ Amnistía Internacional, El sindicalismo en Colombia, Madrid, Amnistía Internacional, 2007, p. 19.

${ }^{27}$ Por el asesinato de Lorcano y Orcasita en marzo de 2010 fue condenado a 30 años de prisión Oscar José Ospino Pacheco alias Tolemaida, Jefe de frente del Bloque Norte de las Auc. "Condenan a alias 'Tolemaida' por homicidio de sindicalistas de la multinacional Drummond”, El Tiempo, 31 de marzo de 2010.

28 Verdad Abierta, "Blanco Maya confiesa que fue el puente entre Drummond y 'paras'”, 19 de abril de 2012.

${ }^{29}$ Hincapié, op. cit., 2013, pp. 379-380. 
entre los sindicatos y dichas organizaciones en su lucha por señalar la avanzada paramilitar en el territorio colombiano y el gran número de víctimas de violaciones a la vida, la libertad y la integridad que el conflicto estaba ocasionando. ${ }^{30}$

Esta movilización de denuncia de la violencia antisindical en el marco del conflicto político armado tuvo como principales estrategias durante más de dos décadas la producción de informes periódicos de denuncia de la violencia, la documentación de las sistemáticas violaciones a los derechos humanos, las denuncias públicas, las demandas judiciales (que presentan un $90 \%$ de impunidad hasta el día de hoy) y el litigio estratégico.

En el ámbito de las demandas que buscaron conexiones transnacionales, en 1998 se presentó por primera vez ante el Comité de Libertad Sindical de la ort el asesinato de siete líderes sindicales durante las marchas llevadas a cabo en el Paro Nacional Sindical promovido por las principales centrales obreras contra el gobierno de Andrés Pastrana (1998-2002). El caso del asesinato de los líderes sindicales se conoció como el "caso 1787", donde se hizo un fuerte llamado al Estado para vigilar las condiciones de violación de derechos humanos que vivían los sindicalistas, además de tener pronunciamientos por parte de Amnistía Internacional y Human Rights Watch, que empezaban a ver con preocupación la situación del sector sindical en términos de violación de derechos humanos.

${ }^{30}$ Entre otras, se dio un espacio focalizado en la "gestión de paz" con vinculación institucional en el que participaron organizaciones las cuales crearon la Red Nacional de Iniciativas por la Paz y contra la Guerra Redepaz en 1993, que junto a grupos de guerrilleros desmovilizados provenientes de la Constituyente de 1991 han buscado trabajar por la paz en medio del conflicto. Véase Mauricio Romero, "Movilizaciones por la paz, cooperación y sociedad civil en Colombia", en Mauricio Archila (eds.), Movimientos sociales, Estado y democracia en Colombia, Bogotá, Universidad Nacional-Icanh, 2001; Mauricio Romero, "Sociedad civil, cooperación y movilización por la paz en Colombia”, en Aldo Panfichi (ed.), Sociedad civil, esfera pública y democratización en América Latina: Andes y Cono Sur, México, FCE, 2002; Flor Alba Romero, "El movimiento de derechos humanos en Colombia", en Movimientos sociales, Estado y democracia en Colombia, Bogotá, Universidad NacionalIcanh, 2001. 
A pesar de lo anterior, la impunidad y la violencia continuaron, por lo cual, y cada vez con mayor intensidad, se organizó una estrategia de socialización y presión internacional por parte de los actores nacionales con el fin de lograr sus objetivos y conseguir resultados.

\section{LA RED DE PRESIÓN TRANSNAGIONAL: NUEVOS MECANISMOS DE MOVILIZACIÓN}

La movilización en defensa de los derechos de los trabajadores sindicalizados en Colombia que se presentó en medio de la negociación del Tratado de Libre Comercio encontró en ésta una "estructura de oportunidad política" 31 para que los actores sociales nacionales tradicionales como los sindicatos y las organizaciones de derechos humanos alentaran sus conexiones con otros actores internacionales influyentes. La movilización confrontó directamente al gobierno de Álvaro Uribe (2002-2010) y la apelación a los derechos humanos permitió la difusión de ideas, prácticas y recursos, configurando diversas alianzas que desbordaron las fronteras nacionales; dichas alianzas posibilitaron la coordinación transnacional de presión contra la violencia antisindical, ensanchando los escenarios tradicionales de movilización de los sindicatos y las organizaciones de derechos humanos locales. ${ }^{32}$

${ }^{31}$ Las estructuras de oportunidades brindan "incentivos para que la gente participe en acciones colectivas al afectar sus expectativas de éxito o fracaso", Sidney Tarrow, El poder en movimiento. Los movimientos sociales, la acción colectiva y la política, Madrid, Alianza, 2009, p. 116.

32 Para hablar de un "movimiento transnacional", debe estar claramente enraizado dentro de las redes sociales y participar en la interacción de manera sostenida. En nuestro caso, no hablamos de un movimiento transnacional, simplemente de una red transnacional que animó un proceso de contienda que afectaba los intereses de un gobierno específico. Al respecto, véase Sidney Tarrow, Strangers at the Gates: Movements and States in Contentious Politics, Cambridge, Cambridge University Press, 2012; Donatella Della Porta, Hanspeter Kriesi y Dieter Rucht, Social Movements in a Globalizing World, Basingstoke, Macmillan, 2009. 


\subsection{Actores colectivos de la red de presión transnacional: intermediación y difusión}

La identificación de los actores que hicieron parte de la red de presión transnacional frente al gobierno de Uribe nos obliga a entender los mecanismos de intermediación ${ }^{33}$ y difusión ${ }^{34}$ que permitieron su funcionamiento. Las redes de presión transnacional se caracterizan por los diferentes nodos tanto en el interior de los Estados objeto de demanda como fuera de ellos; si bien es difícil medir la densidad de las redes, es posible caracterizar los principales actores participantes en la movilización y el rol que jugaron en la acción colectiva coordinada de presión frente al Estado en medio de la negociación del Tratado de Libre Comercio.

La particularidad de la sistemática violencia antisindical en Colombia ubicó al caso colombiano en el centro de las observaciones internacionales, ${ }^{35}$ y bajo diversas estrategias discursivas como "el país más peligroso para ser sindicalista en el mundo", "el país con el $60 \%$ de homicidios a sindicalistas en el planeta", "persecución y violencia antisindical", "estigmatización y marginación de los sindicalistas”. La movilización transnacional se logró articular y generar un conjunto de significados compartidos que valoraban como urgente la acción y la oposición frente a la política de desconocimiento de la violencia antisindical por parte del gobierno nacional.

En el nivel doméstico los principales actores opositores a la firma del TLC que denunciaron la violencia antisindical fueron: el Polo Democrático, una fracción del Partido Liberal y las centrales obreras

${ }^{33}$ Mecanismo que sincroniza y conecta la acción colectiva de diferentes actores previamente desconectados Charles Tilly y Sidney Tarrow, Contentious Politics, Boulder, Paradigm Publisher, 2007.

${ }^{34}$ Mecanismo que propaga una forma de contención, un tema o una manera de enmarcar las demandas de un sitio (terreno) a otro, Tilly y Tarrow, op. cit., 2007.

${ }^{35}$ Como señaló en una entrevista un miembro directivo de las organizaciones que hicieron parte de las demandas: "lo que volvía particular el caso de Colombia es que violaciones de derechos las puedes encontrar en cualquier otro país de América Latina o del mundo, pero el que maten por montones sindicalistas no! Eso lo convierte en una realidad muy colombiana". Entrevista Miembro directivo de la Escuela Nacional Sindical, Medellín, julio de 2011. 
Central Unitaria de Trabajadores (CUT) y la Confederación de Trabajadores de Colombia (СTC), además de las múltiples protestas que se presentaron a lo largo del país por estudiantes, organizaciones sociales y defensores de derechos humanos. La oposición política a la firma del TLC se fundamentó en una desigual negociación de condiciones entre un país con una economía grande, dinámica, y otro con una economía pequeña, sin subsidios para la producción, con una de las tasas de informalidad más altas en el mundo, que lo expone a un deterioro previsible de la industria nacional y a la quiebra de miles de productores agrícolas, ya que no pueden competir de manera eficiente frente a grandes empresas agroindustriales subsidiadas como las de Estados Unidos. ${ }^{36} \mathrm{La}$ denuncia de la violencia antisindical permitió a los actores políticos y a las centrales obreras hacer tanto oposición al Tratado de Libre Comercio (buscando frenar su ratificación) como presión al gobierno colombiano al hacer visible la sistemática violencia contra los sindicalistas la cual había sido negada hasta dicho momento.

En el ámbito de las organizaciones de derechos humanos, la Escuela Nacional Sindical es la ong más importante del país que realiza activismo de producción de información y conocimiento sobre el mundo laboral. ${ }^{37}$ Desde 1989 ha construido la más amplia y confiable base de información estadística y documental sobre las violaciones a la vida, libertad e integralidad de los trabajadores

${ }^{36}$ Un análisis sobre las condiciones de desigualdad que atravesaron la negociación del TLC puede verse en Cecilia López, “¿Cómo se negocia un TLC en Colombia?”, Colombia Internacional, núm. 65, 2007.

${ }^{37}$ Surgida en 1982 en la ciudad de Medellín, sistematiza la información del censo sindical, de las negociaciones colectivas que ocurren en todo el país, construye informes sobre la situación laboral y mantiene un Sistema de Información en el que realiza seguimiento a las violaciones a la vida, libertad e integralidad de los trabajadores sindicalizados, teniendo como horizonte de construcción de información los marcos brindados por la orT y los Tratados Internacionales de Derechos Humanos. Las redes de esta ONG se encuentran integradas en todo el país por diversos comités sindicales, además que hacen parte activa de las plataformas nacionales de derechos humanos y de redes internacionales sindicales. Los miembros de la ENs tienen perfiles diversos, provenientes de la academia, de la formación política de izquierda; la Escuela Nacional busca, a partir de la producción de información y conocimiento, "incidir" en el mundo del trabajo. 
sindicalizados, generando de esta manera una intermediación profesionalizada basada en su expertise en el caso de la violencia antisindical en Colombia. ${ }^{38}$ La intermediación profesionalizada de la ENS se refleja en los acuerdos que tiene con el Grupo Interdisciplinario de Derechos Humanos en Medellín, el Colectivo de Abogados José Alvear Restrepo y la Comisión Colombiana de Juristas en Bogotá, encargándose de documentar las actividades de litigio que tengan que ver con violaciones de derechos humanos a sindicalistas. ${ }^{39}$

Igualmente, como un actor colectivo relevante, encontramos las plataformas nacionales de defensa de los derechos humanos como la Coordinación Colombia Europa Estados Unidos CCEEU, red compuesta por más de cien organizaciones y movimientos que confluyen en una demanda centralizada por el respeto de los derechos de las poblaciones vulneradas, la cual consolida la información de derechos humanos mediante la reunión y la producción de documentos de los cinco nodos regionales (Antioquia, Caribe, Centro, Nororiente, Suroccidente) en el tema priorizado por la Asamblea General que se produce a principios de cada año.

El TLC fue aprobado en el Congreso colombiano por medio de la Ley 1143 de 2007; luego de esta aprobación y la subsecuente declaración de constitucionalidad de la Corte, el TLC pasó a un proceso de ratificación por parte de la Cámara de Estados Unidos, donde tomaron mayor relevancia los actores internacionales. En esta nueva etapa de ratificación entró a jugar roles centrales en la red de demanda de la violencia antisindical en Colombia un grupo de congresistas demócratas estadounidenses encabezado por el senador George Miller. Ellos tomaron como agenda de denuncia dentro del Congreso americano el irrespeto de los derechos a la vida y la libertad que sufrían los sindicalistas en Colombia.

Dentro de la red transnacional, un actor internacional fundamental fue la Federación Estadounidense del Trabajo y Congreso de Organizaciones Industriales (AFL-CIO), la mayor central sindical

38 Jairo López, "Las organizaciones no gubernamentales de derechos humanos en la democracia. Aproximaciones para el estudio de la politización de los derechos humanos en Colombia”, Estudios Políticos, núm. 41, 2012.

39 Entrevista Director General de la Escuela Nacional Sindical, Medellín, agosto de 2011. 
estadounidense, con vínculos directos con la facción de senadores del partido Demócrata y con las centrales sindicales colombianas. Una vez que llegó la discusión al Congreso de los Estados Unidos, fue la AFL-CiO quien socializó la vulneración de los derechos laborales en Colombia, resaltando lo excepcional del contexto de violencia antisindical y cuestionando la ratificación sin condicionamientos del Tratado de Libre Comercio en Estados Unidos.

$\mathrm{Al}$ igual que la AFL-CIO, dentro de los actores internacionales de la red, que se articularon bajo la estructura de oportunidad abierta por la firma y ratificación del Tratado de Libre Comercio, encontramos las organizaciones no gubernamentales internacionales con amplia trayectoria y trabajo en Colombia como Human Rights Watch (HRw) y Washington Office on Latin America (wOLA). Estas organizaciones actuaron como intermediadores para la socialización de la información que dentro del país se producía por parte de las organizaciones no gubernamentales, centrales sindicales y grupos opositores, continuando con una campaña de denuncias que ya había iniciado años atrás y en la que se relacionaba la alarmante situación de asesinatos de los trabajadores sindicalizados con la consolidación del paramilitarismo en el país.

La diferenciación entre el tipo de actores (cuadro 1) permite comprender los roles cumplidos en la red transnacional que se articularon en defensa de los derechos de los trabajadores y el tipo de presión diferenciada sobre el Estado colombiano. En el nivel local encontramos la presencia de actores tradicionales como los propios sindicatos, los partidos políticos, movimientos sociales y las organizaciones no gubernamentales especializadas; en el nivel internacional tenemos actores institucionales gubernamentales como los congresistas estadounidenses, la AFL-CIO como la mayor central sindical norteamericana y organizaciones no gubernamentales con amplia trayectoria de denuncia. Cada tipo de actor en su ámbito de acción fungió como un nodo en una red de demanda y defensa de los derechos de los trabajadores sindicalizados en Colombia, lo que permitió que se combinara la denuncia en espacios institucionales como los congresos, la protesta callejera y la producción de información y la denuncia pública de la violencia antisindical en ambos países. 


\section{Cuadro 1}

Tipo de actores de la red transnacional

\begin{tabular}{|c|c|c|}
\hline Actores & Espacio & Papel de la acción \\
\hline Partidos políticos: & \multirow[t]{2}{*}{ Local } & Denuncia y oposición en el \\
\hline Polo Democrático & & Congreso de Colombia. \\
\hline Alternativo; Partido Liberal. & & \\
\hline Centrales de trabajadores: & \multirow[t]{5}{*}{ Local } & \multirow[t]{5}{*}{ Protesta y oposición en Colombia. } \\
\hline Central Unitaria de & & \\
\hline Trabajadores; Confederación & & \\
\hline de Trabajadores de & & \\
\hline Colombia. & & \\
\hline Organizaciones no & \multirow{4}{*}{$\begin{array}{l}\text { Local e } \\
\text { internacional }\end{array}$} & Producción de información, \\
\hline gubernamentales: & & denuncias judiciales, denuncia \\
\hline ENS; HR W; wOLA; Plataformas & & pública en Colombia y Estados \\
\hline de derechos humanos. & & Unidos. \\
\hline Actores políticos: & \multirow[t]{5}{*}{ Internacional } & Denuncia en el Congreso de \\
\hline Facción de senadores & & Estados Unidos. \\
\hline demócratas en Estados & & \\
\hline Unidos; & & \\
\hline AFL-CIO & & \\
\hline
\end{tabular}

GRÁFICA 2

Diagrama de los mecanismos de la acción coordinada transnacional

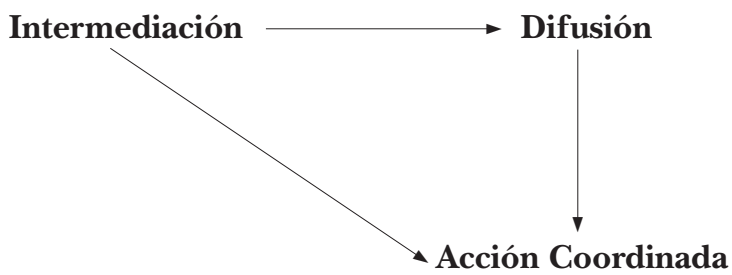

Si bien podemos catalogar como "tradicionales" a todos los actores identificados de la red transnacional, en tanto que cada uno de ellos tiene un repertorio aprendido y una trayectoria de acción 
colectiva sostenida en el tiempo, lo que permitió que la denuncia de la violencia antisindical se difundiera de un lugar a otro y que se presentara una denuncia sostenida fue: 1) el mecanismo de intermediación basado en los diferentes roles y espacios de incidencia de los actores colectivos involucrados que posibilitó conectar la acción colectiva de diferentes actores previamente desconectados; 2) el mecanismo de difusión de la información que señalaba las graves violaciones de los derechos humanos en Colombia, donde los diferentes actores compartieron el marco de demanda de la violación de los derechos humanos por la violencia antisindical (gráfica 2). Dichos mecanismos fueron posibles en medio de la estructura de oportunidad abierta por la negociación del Tratado de Libre Comercio que permitió visibilizar demandas sobre una crisis de derechos humanos que no había sido reconocida hasta dicho momento y que ubicó al gobierno colombiano en el centro de críticas de diversos actores.

\subsection{La información como motor de conflicto}

Como ha sido demostrado en diversos estudios, la producción de información y conocimiento es central en la política de avergonzamiento sobre los Estados, en tanto recurso especial con el que cuentan los actores no institucionales para difundir sus demandas y promover la acción coordinada. ${ }^{40}$ Hasta el momento de las conexiones transnacionales en denuncia de la violencia antisindical en Colombia, los gobiernos habían negado la crisis de derechos humanos; al presentarse el proceso de socialización de información como acción coordinada, en medio de la ventana de oportunidad de la negociación del TLC, la reacción del gobierno fue de confrontación y ataque a los actores colectivos que denunciaban la violencia antisindical. ${ }^{41}$

${ }^{40}$ Keck y Sikkink, op. cit., 2000; Burgerman, op. cit., 2001.

${ }^{41}$ Para el Gobierno, la firma del Tratado era una prioridad, por lo cual formó un equipo de altos expertos que llevaron adelante las negociaciones y promovió en el interior del país la imagen de que el TLC daría mayores oportunidades a los empresarios colombianos para entrar a competir en la mayor economía del mundo y garantizaría, como mínimo, un crecimiento anual del 1\% del PIB. Laura Silva, 
La respuesta gubernamental al trabajo de los actores domésticos en la producción información se caracterizó por una confrontación metodológica de las cifras presentada. Desde 2004 el gobierno nacional empezó a construir sus propias cifras sobre violaciones de derechos humanos de los trabajadores sindicalizados en Colombia; sin embargo, la estrategia del gobierno llevó a un subregistro de los sindicalistas asesinados porque no fueron incluidos aquellos asesinatos cuyos presuntos autores fuesen las organizaciones de coerción estatal (ejército y policía). Como resultado las cifras de asesinatos a sindicalistas eran inferiores casi en un $50 \%$ en comparación con las organizaciones de derechos humanos y sindicatos. ${ }^{42}$

Este conflicto por las cifras se evidenció con la publicación del informe en 2007 titulado "2515 o esa siniestra facilidad para olvidar", donde se afirmaba que Colombia era el "país del mundo más peligroso para el sindicalismo, en el que ocurren más de $60 \%$ de los homicidios a trabajadores sindicalizados del planeta". ${ }^{43}$ La AFL-CIO presentó las cifras del informe en el Congreso de Estados Unidos y se empezó a dirigir la discusión sobre la ratificación del TLC al problema de la violación de derechos humanos de los sindicalistas en Colombia; se argumentó que estas violaciones a los derechos iban en contra de los convenios firmados y ratificados por Colombia ante la oIT. ${ }^{44}$ De esta

"El proceso de negociación del TLC entre Colombia y Estados Unidos", Colombia Internacional, núm. 65, 2007; Jorge Pulecio, "La estrategia Uribe de negociación del TLC”, Colombia Internacional, núm. 61, 2005.

42 Esta situación se refleja en las palabras del director de la Escuela Nacional Sindical: "cada vez que él [Uribe] decía un discurso, tocaba al otro día salir a aclarar todo el tiempo. Todos los organismos internacionales nos pedían el listado cada vez que él decía un discurso; entonces eso era una guerra de listas [...] entonces todo el tiempo el trabajo de nosotros era cada que Uribe hacía una declaración, cada que un embajador o que las embajadas mandaran un informe, porque empezaron a hacer informes mensuales. Eso nos cambió toda la vida. El gobierno empezó a hacer informes mensuales y mandarlos a todas las embajadas, a hacer reuniones con todos los gobiernos cercanos y diplomacia en contra de la diplomacia de derechos humanos de nosotros”. Entrevista al Director General ens, Medellín, agosto de 2011.

${ }^{43}$ Escuela Nacional Sindical, 2515 o esa siniestra facilidad para olvidar. Veintiún años de asesinatos sistemáticos y selectivos contra sindicalistas en Colombia (1986-2006), Medellín, Ens, 2007. (Cuaderno de Derechos Humanos, núm. 19)

${ }^{44}$ Como respuesta a estas actividades, el vicepresidente Santos arremetió públicamente en Washington contra las ONG y sindicalistas, diciendo que la campaña 
manera, la combinación del marco de demanda de la violencia antisindical y la producción de información estratégica se combinaron produciendo mecanismos de intermediación y difusión que permitieron una acción coordinada transnacional en forma de red de defensa.

El argumento que se presentó por parte de la red transnacional de defensa fue la existencia de una "cultura antisindical", ${ }^{45}$ la cual provocaba una múltiple exclusión de los sindicatos en el país (social, institucional, política, económica), que se reflejaba en los altos índices de violación de derechos de los trabajadores y la poca respuesta institucional que se daba para superar dicha situación. Valiéndose de las recomendaciones dadas por la oIT y la Oficina del Alto Comisionado de Naciones Unidas, las ONG argumentaron que estas exclusiones se materializaban en los índices de violencia contra los sindicalistas y los altos índices de impunidad por parte de la Fiscalía General en las investigaciones de los casos existentes. ${ }^{46}$ En medio de los reclamos y de la negociación de la ratificación del TLC, el director de Human Rights Watch, con los informes en mano provenientes de la ENS y de la CCEEU, pidió al Congreso estadounidense solicitar que se usara dicha negociación de ratificación "para presionar en materia de derechos humanos al gobierno nacional". ${ }^{47}$ Además del cabildeo en el Congreso, HRw elaboró un informe sobre el proceso de desmovilización paramilitar y la impunidad que se presentaba en el

contra el TLC que llevaban en Estados Unidos era "ideológica, financiera y política, [agregando que] creen que el 78\% de los colombianos somos estúpidos". "Santos: creen que $78 \%$ de los colombianos son estúpidos”, El Tiempo, 25 de mayo de 2007. El gobierno superponía su popularidad y el apoyo electoral a las demandas por los mínimos de los derechos humanos, señalando que su defensa era un "negocio que impide reconocer los avances del Gobierno".

${ }^{45}$ Escuela Nacional Sindical, Informe sobre las violaciones a los derechos humanos de los y las sindicalistas colombianos en el año 2007, Medellín, ENs, 2008. (Cuaderno de Derechos Humanos, núm. 20)

${ }^{46}$ Escuela Nacional Sindical, No es muda la muerte. Informe sobre la violación a la vida, libertad e integridad de las y los sindicalistas en Colombia durante 2008 y situación de impunidad de las violaciones en el período 1986-2009, Medellín, ENs, 2009. (Cuaderno de Derechos Humanos, núm. 21)

47 "Piden que el TLC se use para presionar a Uribe", El Tiempo, 25 de enero de 2008. 
caso de la justicia en torno al asesinato y persecución de sindicalistas perpetrada por este actor armado. ${ }^{48}$

Estas disputas confluyeron en el año 2009 en una confrontación por el sentido y la interpretación de la información materializada en diferentes informes que se produjeron cuestionando la idea de una "cultura antisindical" y de una "violencia sistemática contra los sindicalistas". Bajo el argumento de que el TLC con Estados Unidos estaba bloqueado por "la demagogia y lobby con el fin de proteger intereses particulares", ${ }^{49}$ se realizó una interpretación estadística de los datos producidos por la ens y la Vicepresidencia de la República según la cual en Colombia no existía violencia antisindical, sino los efectos colaterales de un contexto generalizado de violencia por el conflicto armado del que toda la población era víctima. ${ }^{50}$ Dicha argumentación estadística, aunada a las declaraciones constantes del presidente Uribe según las cuales en Colombia una cuarta parte de las personas con protección individual eran líderes sindicales (1500), buscó desacreditar la información producida por las ONG y minimizar la crisis de violación de derechos de los trabajadores sindicalizados.

El Gobierno nacional planteó entonces un "complot" contra la "nación" por parte de quienes denunciaron el problema sindical en el exterior, además de que presentó a la ENs ante las embajadas como "traficante de cadáveres"; es decir, a partir de una ofensiva diplomática se buscó crear la idea de que la ens inflaba las cifras de homicidios contra sindicalistas con finalidades políticas dado que, según el gobierno nacional, "entre más muertos reporten, mayor cooperación reciben". 51

${ }^{48}$ Human Rights Watch, ¿̨Rompiendo el control? Obstáculos a la justicia en las investigaciones de la mafia paramilitar en Colombia, Nueva York, HRw, 2008.

49 Daniel Mejía, "La seguridad de los sindicalistas y el bloqueo del TLC", en Documento de Trabajo, Bogotá, Universidad de los Andes, 2009.

${ }^{50}$ Daniel Mejía y María José Uribe, "Is Violence Against Union Members in Colombia Systematic and Targeted?”, en Documentos CEDE, Bogotá, Universidad de los Andes, 2009.

51 Tales argumentos son presentados en el libro de Libardo Botero, El gran fraude ¿̇Violencia antisindical en Colombia? Historia de la conspiración contra el TLC, Bogotá, 2011. 
Como respuesta a estos informes que fueron apropiados por el gobierno, la ENs contrató al programa de derechos humanos de la empresa estadounidense Benetech, experta en asesoría técnica y metodológica en investigaciones estadísticas. Luego de un análisis detallado sobre las conclusiones de los informes presentados por el gobierno nacional, se encontró que existían graves deficiencias metodológicas que llevaban a concluir que la violencia contra los sindicalistas no era ni sistemática ni dirigida; ${ }^{52}$ dicho informe se utilizó para cuestionar los argumentos del gobierno tanto a nivel nacional como en todas las redes de presión a nivel internacional. Estas disputas especializadas dan muestra de la sutileza de la discusión y de la confrontación en el plano internacional, donde la presión de la red transnacional se concentró en demostrar que sí existía un problema de violación de los derechos humanos de un sector especial de la población, el sindicalizado, lo cual iba en contra de los convenios firmados en la orT y en las instancias internacionales de derechos humanos.

\subsection{Efectos materiales y simbólicos de la movilización transnacional}

Durante el primer periodo de gobierno del presidente Barack Obama (2009-2012), los congresistas estadounidenses que hicieron parte de la red transnacional de denuncia de la violencia antisindical pidieron que fuese reducida la ayuda militar y económica a Colombia hasta que no hubiese cambios de fondo en la política frente a los sindicalistas y las organizaciones de derechos humanos. ${ }^{53} \mathrm{La}$ contundencia de las cifras según las cuales durante los años 2002 y 2009 las ejecuciones extrajudiciales contra sindicalistas aumentaron $250 \%$ en comparación con los siete años anteriores fue retomada en las redes de presión y en el cabildeo internacional. A finales del gobierno de Uribe en 2010, y tras su salida, una Comisión de

52 Megan Price y Daniel Guzmán, Comentarios al artículo “ ¿Es la violencia antisindical en Colombia sistemática y dirigida?”, Programa de Derechos Humanos de Benetech, California, Benetech, 2010.

53 "Demócratas piden reducir ayuda de E.U. a Colombia", El Tiempo, 19 de noviembre 2009 . 
seis Representantes de la Cámara estadounidense le envió un informe/memorando al presidente Obama sobre la ratificación del TLC donde señalaban:

Colombia sigue siendo calificada por la Confederación Sindical Internacional como el país más peligroso del mundo para los sindicalistas, con un número anual de asesinatos que frecuentemente llega a igualar o a exceder la suma de asesinatos registrados en los demás países. La violencia contra los sindicalistas colombianos continúa imparable, y en la mayoría de los casos nadie ha sido responsabilizado. La Organización Internacional del Trabajo (OIT) ha reportado que el gobierno colombiano no ha proveído, ni en las leyes, ni en la práctica, los derechos fundamentales de los trabajadores y que ha fallado en cumplir efectivamente estas leyes. ${ }^{54}$ Concluyó este memorando con la recomendación de cinco amplias medidas que se deberían exigir al gobierno colombiano para la ratificación del tratado, medidas en las que se buscaba implementar mecanismos institucionales de garantía y protección de los derechos fundamentales de los trabajadores.

Las condiciones interpuestas por el gobierno de Estados Unidos obligaron, primero, a la implementación de un plan integral de protección de líderes sindicales y trabajadores amenazados (fortaleciendo la unidad de la Fiscalía especializada previamente existente). Segundo, a la firma de un Plan de Acción Colombia y Estados Unidos para los Derechos Laborales en los que se señaló: 1) la creación de un Ministerio de Trabajo, 2) reforma al código penal, 3) reforma a las cooperativas de trabajo asociado, 4) control a las empresas de servicios temporales, 5) el control a los pactos colectivos, 6) servicios esenciales, 7) cooperación y asesoramiento con la oIT, 8) un programa fortalecido de protección a la vida de los sindicalistas, 9) reforma a la justicia penal y 10) mecanismos de seguimiento. ${ }^{55}$

${ }^{54}$ James McGovern et al., "Avances en los Derechos Humanos y Laborales en Colombia y la consideración en el Congreso estadounidense del Tratado de Libre Comercio entre los EEUU y Colombia”, Memorando de Congresistas de E. U. a Barack Obama, Washington, 17 de marzo de 2010. Disponible en http:/ / ens.org.co/index. shtml?apc=a-;-;20166376;-20166376;\&x=20166376

55 Vicepresidencia de la República, Plan de Acción Colombia y Estados Unidos para los Derechos Laborales, Colombia, 2011. 
Tercero, se obligó al gobierno nacional y a las instituciones encargadas a discutir las cifras presentadas. Aunque no se llegó a un consenso sobre las cifras, se subrayó la condición de estigmatización y persecución a la que son sometidos los sindicalistas en el país. ${ }^{56}$

Otro referente esclarecedor de los efectos simbólicos de la presión ejercida por la red de defensa de los derechos humanos frente a la violencia antisindical en Colombia es el Informe del Examen Periódico Universal del 2013 de las Naciones Unidas, donde se señala con claridad que los sindicalistas en Colombia son reconocidos como "defensores de derechos humanos" y su situación está marcada por la "impunidad y la victimización". ${ }^{57}$ A pesar de la fuerte confrontación del gobierno de Álvaro Uribe mientras se presentó la oposición y crítica a la firma del Tratado de Libre Comercio, los sindicalistas lograron obtener el reconocimiento internacional como población objeto de persecución y violaciones graves de sus derechos, siguiendo una estratégica política que buscó la coordinación internacional.

Con todo, la movilización de la red de presión transnacional tuvo efectos materiales visibles que se concretaron en la firma del Plan de Acción Laboral (PAL) que condicionó la ratificación del tratado comercial a una reforma institucional buscando corregir, o atender, la grave crisis de derechos humanos de los trabajadores sindicalizados, y a la creación de una política integral de derechos humanos en el país concertada con las organizaciones de derechos humanos, entre otras. ${ }^{58}$

Por otro lado, los efectos simbólicos se encuentran en el reconocimiento que tanto Naciones Unidas como el gobierno nacional debieron hacer de la violencia antisindical y el rechazo de la tesis según la cual los homicidios, amenazas y atentados contra los trabajadores colombianos eran daños colaterales de la guerra. Por el contrario, se debió reconocer un comportamiento sistemático del Estado tanto en la omisión como en la participación en la violencia antisindical.

56 PNUD, Reconocer el pasado. Construir el futuro. Informe sobre violencia contra sindicalistas y trabajadores sindicalizados 1984-2011, Bogotá, PNUD, 2012.

${ }^{57}$ Informe del Examen Periódico Universal para Colombia, mayo de 2013.

58 "TLC entre Colombia y Estados Unidos entra en vigor casi 6 años después de su firma”, El Espectador, 10 de mayo de 2012. 


\section{Conclusiones}

En el presente artículo demostramos cómo las redes de presión transnacional fueron efectivas en la reivindicación y denuncia de la grave crisis de derechos humanos que representa la violencia antisindical en Colombia, supliendo de esta manera las formas tradicionales de movilización de los sindicatos, las cuales a pesar de haber ejercido una denuncia constante no habían logrado ningún reconocimiento de la gravedad de las violaciones por parte del Estado. Tan sólo hasta la negociación y ratificación del Tratado de Libre Comercio con Estados Unidos (constituida como una estructura de oportunidad), una serie de actores articulados a manera de red de presión transnacional logró evidenciar públicamente la crisis de derechos humanos y emitir sanciones, tanto materiales como simbólicas sobre el Estado colombiano.

La presión transnacional en medio de las negociaciones por la ratificación del TLC se concentró en la denuncia de las graves violaciones a los derechos humanos de los sindicalistas en Colombia, basada en los lineamientos de los tratados de derechos humanos y en los convenios firmados con la OIT en materia de derechos laborales, lo cual permitió organizar intermediaciones y difusión. La defensa de los derechos de los trabajadores respondió a la apropiación del repertorio de los derechos humanos como una herramienta que dio viabilidad y visibilidad a una trayectoria de demandas históricas de actores gravemente perseguidos y victimizados por los gobiernos nacionales y la propia lógica de la guerra.

La conexión e intermediación entre diversos sindicatos, organizaciones de derechos humanos, actores políticos, organizaciones no gubernamentales internacionales y sindicatos internacionales encontraron en el marco de la violencia antisindical un conjunto de significados compartidos a partir de los cuales orientaron su acción a demandar el reconocimiento de los derechos civiles y políticos de los trabajadores colombianos. La persecución, estigmatización y marginación de los sindicalistas en Colombia, intensificadas en los últimos treinta años bajo la expansión del paramilitarismo y las dinámicas de la guerra, condujeron a escenarios de solidaridad y difusión en los que la acción profesionalizada en la producción de información 
valió como recurso especial en la movilización transnacional. Dadas las estructuras de oportunidad abiertas por la negociación del Tratado de Libre Comercio, el activismo transnacional rindió resultados diferenciados: de agentes internacionales que ejercieron presión material sobre el gobierno colombiano y la visibilización de la violencia antisindical dentro del país, y una crisis humanitaria que fue negada incluso en los momentos más álgidos de la guerra en Colombia.

La firma del Plan de Acción Laboral constituyó sin lugar a dudas un éxito de la redes de presión transnacional al comprometer al gobierno colombiano a llevar a cabo una serie de medidas previas a la ratificación del TLC relacionadas con las demandas de las organizaciones de derechos humanos.

A pesar de lo anterior, en abril de 2014 fue presentado el informe "Evaluación del cumplimiento de las medidas adoptadas con ocasión del Plan de Acción Laboral" elaborado por la Central Unitaria de Trabajadores, la Confederación de Trabajadores de Colombia, la Red Colombiana de Acción frente al Libre Comercio (Recalca) y la Escuela Nacional Sindical, donde se deja en evidencia el incumplimiento de los acuerdos firmados en dicho Plan dado que se implementaron treinta medidas de manera parcial e insuficiente, mientras que otras siete medidas no han sido implementadas aún, ${ }^{59}$ entre ellas el análisis conjunto y acuerdos sobre los casos de violencia antisindical a investigar por parte de la Fiscalía. El informe subraya que el incumplimiento de los acuerdos firmados en el PAL en buena medida obedece a la ausencia de mecanismos efectivos para garantizar que los acuerdos se cumplieran plenamente ya que, una vez ratificado el TLC, los incipientes

59 i) Mejoramiento del sistema de mediación y resolución de conflictos; ii) implementación de un régimen para prevenir el uso indebido de las empresas de servicios temporales; iii) informes sobre el comportamiento laboral de estas empresas; iv) campaña sobre uso ilegal de los pactos colectivos; v) inspección laboral preventiva para el uso ilegal de pactos colectivos; vi) compilación y difusión de la doctrina y la jurisprudencia sobre servicios esenciales; vii) análisis de casos cerrados y acuerdos sobre la lista de casos de violencia antisindical a investigar, orientación interna de la Fiscalía para impulsar casos con indicios y cerrar provisionalmente los "casos fríos" y el impulso de casos priorizados. 
procesos iniciados no tuvieron continuidad; del mismo modo se denunció que desde abril de 2011 a febrero de 2014 han sido asesinados 73 sindicalistas, 31 han sufrido atentados de muerte, se han presentado 6 desapariciones forzadas y 953 amenazas de muerte. ${ }^{60}$ En este panorama las centrales sindicales y las organizaciones de derechos humanos acompañantes consideran que: "La inadecuada implementación del PAL indica que el Gobierno Colombiano podría haber estado más interesado en congraciarse con el Gobierno y el Congreso de Estados Unidos que en revertir la informalidad, la tercerización, la precariedad laboral, las prácticas antisindicales, la violencia antisindical y la impunidad de los crímenes cometidos contra sindicalistas". ${ }^{61}$

Como vimos, la movilización en defensa de derechos humanos en Colombia ha tenido logros importantes, en este caso concreto producto de la acción de una red transnacional que llevó a cabo la acción colectiva. Asimismo, podemos advertir el comportamiento cínico por parte de los gobiernos nacionales frente a las masivas violaciones de derechos humanos en tanto que se firman acuerdos y se ratifican tratados internacionales. Al mismo tiempo, en los hechos, perviven las graves y sistemáticas violaciones a los individuos y colectividades que dicen proteger, con que se evidencia la necesidad de hacer un esfuerzo mayor de socialización dentro de un país en el cual se precisa una mayor valoración y un compromiso real por el respeto de los derechos humanos.

\section{BibLIOGRAFÍA}

Aikin, Olga y Alejandro Anaya, "Crisis de derechos humanos de las personas migrantes en tránsito por México: redes y presión transnacional”, Foro Internacional, vol. 53, núm. 1, 2013.

Alba Romero, Flor, "El movimiento de derechos humanos en Colombia",

${ }^{60}$ Confederación de Trabajadores de Colombia y Central Unitaria de Trabajadores, Tres años de incumplimiento del Plan de Acción Obama-Santos. Informe sobre los tres primeros años de implementación del PAL, Bogotá, CTC-CUT, 2014, p. 25.

61 Ibid., p. 8. 
en Movimientos sociales, Estado y democracia en Colombia, Bogotá, Universidad Nacional-Icanh, 2001.

Amnistía Internacional, El sindicalismo en Colombia, Madrid, Amnistía Internacional, 2007.

Anaya, Alejandro, "Los derechos humanos desde las relaciones internacionales: normas, regímenes, emprendedores y comportamiento estatal", en Ariadna Estévez, y Daniel Vázquez (coord.), Los derechos humanos en las ciencias sociales. Una perspectiva multidisciplinaria, México, Flacso-Cisan-unam, 2010.

Anaya, Alejandro, El país bajo presión. Debatiendo el papel del escrutinio internacional de derechos humanos sobre México, México, CIDE, 2012.

Archila, Mauricio, Cultura e identidad obrera: Colombia 1910-1945, Bogotá, Cinep, 1991.

— , "Luchas laborales y violencia contra el sindicalismo en Colombia 2002-2010. ¿Otro daño colateral de la seguridad democrática?”, Revista Controversia, núm. 198, 2012.

Benford, Robert y David Snow, "Framing Processes and Social Movements: An Overview and Assessment”, Annual Review of Sociology, vol. 26, 2000.

Bergquist, Charles, Los trabajadores en la historia latinoamericana. Estudios comparativos de Chile, Argentina, Venezuela y Colombia, Bogotá, Siglo XXI, 1988.

_ "Los trabajadores del sector cafetero y la suerte del movimiento obrero en Colombia 1920-1940”, en Gonzalo Sánchez y Ricardo Penaranda (coords.), Pasado y presente de la violencia en Colombia, Medellín, La Carreta, 2007.

Botero, Libardo, El gran fraude. ¿ Violencia antisindical en Colombia? Historia de la conspiración contra el TLC, Bogotá, Fundación Internacionalismo Democrático / Fundación Centro de Pensamiento Primero Colombia, 2011.

Burgerman, Susan, Moral Victories: How Activists Provoke Multilateral Action, Ithaca, Cornell University Press, 2001.

Cárdenas, Sonia, Conflict and Compliance: State Responses to International Human Rights Pressures, Philadelphia, University of Pennsylvania Press, 2007.

Comisión Colombiana de Juristas y Escuela Nacional Sindical, Imperceptiblemente nos encerraron. Exclusión del sindicalismo y lógicas de la violencia antisindical en Colombia 1979-2010, Bogotá, ENS-CCJ, 2012. 
Confederación de Trabajadores de Colombia y Central Unitaria de Trabajadores, Tres años de incumplimiento del Plan de Acción Obama-Santos. Informe sobre los tres primeros años de implementación del PAL, Bogotá, CTCCUT, 2014.

CUT, CGT y CTC, Los derechos laborales y las libertades sindicales en Colombia, Bogotá, s. e., 2007.

Delgado, Álvaro, "El conflicto huelguístico colombiano, 1961-1990", en ¿Dónde está la clase obrera? Huelgas en Colombia 1946-1990, Bogotá, Cinep, 1995.

Della Porta, Donatella, Hanspeter Kriesi y Dieter Rucht, Social Movements in a Globalizing World, Basingstoke, Macmillan, 2009.

Dezalay, Yves y Bryant Garth, "From the Cold War to Kosovo: The Rise and Renewal of the Field of International Human Rights", Annual Review of Law and Social Science, núm. 2, 2006.

EEUU contra Chiquita Brands International: Memorando de Condena del Gobierno. Juzgado del Distrito de Columbia, EE.UU., No. Criminal 07-055 (RCL), 17 de septiembre de 2007.

Escuela Nacional Sindical, 2515 o esa siniestra facilidad para olvidar. Veintiún años de asesinatos sistemáticos y selectivos contra sindicalistas en Colombia (1986-2006), Medellín, ENs, 2007. (Cuaderno de Derechos Humanos, núm. 19)

- Informe sobre las violaciones a los derechos humanos de los y las sindicalistas colombianos en el año 2007, Medellín, ENs, 2008. (Cuaderno de Derechos Humanos, núm. 20)

- No es muda la muerte. Informe sobre la violación a la vida, libertad e integridad de las y los sindicalistas en Colombia durante 2008 y situación de impunidad de las violaciones en el periodo 1986-2009, Medellín, ENs, 2009. (Cuaderno de Derechos Humanos, núm. 21)

Garth, Bryant, "The Globalization of the Law", en The Oxford Handbook of Law and Politics, Oxford, Oxford University Press, 2008.

Hagan, Margaret, "The Human Rights Repertorie: Its Strategic Logic, Expectations and Tactics", International Journal of Human Rights, vol. 14, núm. 4, 2011, p. 559.

Hincapié, Sandra, La guerra en las ciudades, Medellín, IPC, 2005.

-, "Estado y región: Colombia y Perú en perspectiva comparada", en ¿Prolongación sin solución? Perspectivas sobre la guerra y la paz en Colombia, Bogotá, Universidad Externado de Colombia, 2012. 
, "Órdenes yuxtapuestos. Dinámicas contenciosas, reformas estatales y crimen organizado en México y Colombia”, tesis de doctorado, México, Flacso, 2013.

Human Rights Watch, ¿Rompiendo el control? Obstáculos a la justicia en las investigaciones de la mafia paramilitar en Colombia, Nueva York, HRw, 2008.

Informe del Examen Periódico Universal para Colombia, mayo de 2013. Keck, Margaret y Kathryn Sikkink, Activistas sin fronteras. Redes de defensa en política internacional, México, Siglo XXI, 2000.

Khagram, Sanjeev, James Riker y Kathryn Sikkink, Restructuring World Politics: Transnational Social Movements, Networks, and Norms, Minneapolis, University of Minnesota Press, 2002.

López, Cecilia, “¿Cómo se negocia un TLC en Colombia?”, en Colombia Internacional, núm. 65, 2007.

López, Jairo, "Las organizaciones no gubernamentales de derechos humanos en la democracia. Aproximaciones para el estudio de la politización de los derechos humanos en Colombia”, Estudios Políticos, núm. 41, 2012.

, "Los derechos humanos en movimiento. Una revisión teórica contemporánea”, Revista Espiral. Estudios de Estado y Sociedad, núm. 56, 2013.

Maza, Emma, Derechos humanos. México: retórica sin compromiso, México, Flacso, 2009.

McGovern, James et al., "Avances en los Derechos Humanos y Laborales en Colombia y la consideración en el Congreso estadounidense del Tratado de Libre Comercio entre los EEUU y Colombia", Memorando de Congresistas de E. U. a Barack Obama, Washington, 17 de marzo 2010. Disponible en http://ens.org.co/index.shtml?apc=a-;-;20166376;20166376;\&x=20166376

Mejía, Daniel "La seguridad de los sindicalistas y el bloqueo del TLC", en Documento de Trabajo, Bogotá, Universidad de los Andes, 2009.

Mejía, Daniel y María José Uribe, "Is Violence Against Union Members in Colombia Systematic and Targeted?”, en Documentos CEDE, Bogotá, Universidad de los Andes, 2009.

oEA, "Informe de la Secretaría General sobre el desvío de armas nicaragüenses a las Autodefensas Unidas de Colombia”, 29 de enero de 2002.

Pecaut, Daniel, Política y sindicalismo en Colombia, Bogotá, La Carreta, 1973. 
Pereira, Alexander, "Violencia en el mundo sindical. Un análisis cualitativo sobre una práctica persistente en Colombia, 1986-2011", Revista Controversia, núm. 198, 2012.

PNUD, Reconocer el pasado. Construir el futuro. Informe sobre violencia contra sindicalistas y trabajadores sindicalizados 1984-2011, Bogotá, PNUD, 2012.

Price, Megan y Daniel Guzmán, Comentarios al artículo “¿Es la violencia antisindical en Colombia sistemática y dirigida?", Programa de Derechos Humanos de Benetech, California, Benetech, 2010.

Pulecio, Jorge, "La estrategia Uribe de negociación del TLC", Colombia Internacional, núm. 61, 2005.

Risse, Thomas, Stephen Ropp y Kathryn Sikkink, The Power of Human Rights: International Norms and Domestic Change, Cambridge, Cambridge University Press, 1999.

Romero, Mauricio, "Movilizaciones por la paz, cooperación y sociedad civil en Colombia", en Mauricio Archila (eds.), Movimientos sociales, Estado y democracia en Colombia, Bogotá, Universidad Nacional-Icanh, 2001.

Romero, Mauricio, "Sociedad civil, cooperación y movilización por la paz en Colombia”, en Aldo Panfichi (ed.), Sociedad civil, esfera pública y democratización en América Latina: Andes y Cono Sur, México, FCE, 2002.

Sikkink, Kathryn, "La dimensión transnacional de los movimientos sociales", en Elizabeth Jelin, Más allá de la nación: las escalas múltiples de los movimientos sociales, Buenos Aires, Libros del Zorzal, 2003.

Silva, Laura, "El proceso de negociación del TLC entre Colombia y Estados Unidos”, en Colombia Internacional, núm. 65, 2007.

Simmons, Beth, Mobilizing for Human Rights: International Law in Domestic Politics, Cambridge, Cambridge University Press, 2009.

Snow, David y Robert Benford, "Alternative Types of Cross-national Diffusion in the Social Movement Arena", en Social Movements in a Globalizing World, Basingstoke, Macmillan, 2009.

Stammers, Neil, Human Rights and Social Movements, Londres, Pluto Press, 2008.

Tarrow, Sidney, The New Transnational Activism, Cambridge, Cambridge University Press, 2005.

— El poder en movimiento. Los movimientos sociales, la acción colectiva y la política, Madrid, Alianza, 2009.

-, Strangers at the Gates: Movements and States in Contentious Politics, Cambridge, Cambridge University Press, 2012. 
Tilly, Charles y Sidney Tarrow, Contentious Politics, Boulder, Paradigm Publisher, 2007.

Vicepresidencia de la República, Plan de Acción Colombia y Estados Unidos para los Derechos Laborales, Colombia, 2011.

Notas periodísticas y entrevistas

"Banana 'para-republic', Revista Semana, 17 de marzo de 2007.

"Blanco Maya confiesa que fue el puente entre Drummond y 'paras'”, Verdad Abierta, 19 de abril de 2012.

"Condenan a alias 'Tolemaida' por homicidio de sindicalistas de la multinacional Drummond", El Tiempo, 31 de marzo de 2010.

"Demócratas piden reducir ayuda de E.U. a Colombia", El Tiempo, 19 de noviembre 2009.

"La verdad no se cuenta en un día", El Colombiano, 13 de julio de 2008.

"Piden que el TLC se use para presionar a Uribe", El Tiempo, 25 de enero de 2008.

"Santos: creen que 78\% de los colombianos son estúpidos", El Tiempo, 25 de mayo de 2007.

“TLC entre Colombia y Estados Unidos entra en vigor casi 6 años después de su firma”, El Espectador, 10 de mayo de 2012.

Entrevista al Director General ENs, Medellín, agosto de 2011.

Entrevista Director General de la Escuela Nacional Sindical, Medellín, agosto de 2011.

Entrevista Miembro directivo de la Escuela Nacional Sindical, Medellín, julio de 2011. 